\title{
A NUMERICAL INVESTIGATION OF NON-ROTATIONAL, RIGID SPHERICAL PARTICLE SEDIMENTATION PROBLEM IN VISCOUS FLUID
}

\author{
Nguyen Hong Phan, Nguyen Van Diep \\ Institute of Mechanics, NCST, 264 Doican, Hanoi, Vietnam
}

\begin{abstract}
This paper can be considered as continuous part of [1], where the generalized diffusion theory of rigid spherical particle sedimentation in viscous fluid was investigated. Here a numerical solution of non-stationary sedimentation process is obtained by using the explicit finite difference method. The obtained results show that this model can be used for qualitative study of physical phenomenon of sedimentation problem.
\end{abstract}

\section{The Governing Equation System}

Let's consider a sedimentation process of rigid, spherical, non-rotational particles in a viscous suspension filled up the space between two horizontal parallel planes separated by the vertical distance $L$ (Fig. 1). It is assumed that the suspension is in a initial stationary state and being forced only by the gravity.

In this case the movement of particles under the gravity force is considered only in the vertical $z$ direction, and there is not a mean volume suspension velocity. Therefore $\varphi, \bar{J}, p$ are functions of variables $(t, z)$ :

$$
\varphi=\varphi(t, z) ; \quad \bar{J}=(0,0, J) ; \quad J=J(t, z) ; \quad P=P(t, z)
$$

On basis of above mentioned assumptions, the equation system has the following form:

$$
\begin{aligned}
& \frac{\partial \varphi}{\partial t}+\frac{1}{\rho_{1}} \frac{\partial J}{\partial z}=0 \\
& \frac{\partial J}{\partial t}+K_{1} \frac{\varphi(1-\varphi)}{1+\varphi\left(k_{\rho}-1\right)} J+K_{2} \frac{\varphi(1-\varphi)}{1+\varphi\left(k_{\rho}-1\right)}+\frac{D \varphi}{1+\varphi\left(k_{\rho}-1\right)} \frac{\partial \varphi}{\partial z}=0
\end{aligned}
$$

And after determination of $\varphi$ and $J$ we can define the pressure $p$ by:

$$
\frac{\partial P}{\partial z}+\rho_{1} g\left[k_{\rho}-\varphi\left(k_{\rho}-1\right)\right]-\left(k_{\rho}-1\right) \frac{\partial J}{\partial t}=0
$$

In addition, in (1.2) and (1.3) it was supposed that:

$$
D=\left(\frac{\partial \mu_{1}}{\partial \varphi}\right)_{p, T} \rho_{1}=\mathrm{const} ; K_{1}=\frac{T \rho_{1}}{\alpha_{11}}=\mathrm{const} ; K_{2}=\left(\rho_{1}-\rho_{2}\right) g=\mathrm{const} ; k_{\rho}=\frac{\rho_{2}}{\rho_{1}}
$$


where: $\rho_{1}, \rho_{2}, \rho$-densities of particle, fluid phase and suspension; $\bar{J}$ - particle generalized diffusion flux; $\varphi$ - particle volume concentration; $P$-thermodynamically pressure; $T$ - temperature of suspension; $\mu_{1}$ - generalized chemical potential of particles; $\alpha_{i}, \beta_{i}$ - constitutive coefficients; $g$ - acceleration of gravity; $t$ - time; $z$ - space coordinate.

In order to determine the volume concentration $\varphi$ and diffusion flux $\bar{J}$ of particles, the following conditions are used:

- Initial conditions: at $\mathrm{t}=0$ :

$$
\begin{aligned}
& \varphi=\varphi_{0}=\text { constant } ; \quad 0<\varphi<1 ; \\
& J=J_{0}=0
\end{aligned}
$$

- Boundary conditions:

$$
\begin{array}{rlrl}
\text { on } z=0 & & J=0 \\
\text { on } z=L & J & =0 \\
& P=\text { const }
\end{array}
$$

where $L$ is the distance between the parallel planes.

\section{The Numerical Formulation}

\section{a) The finite-difference equation system $[2,3]$}

It is clear that equation system (1.2) is nonlinear. We will use an explicit approach with finite-difference technique for its numerical solution.

We consider the grid system, indicated in Fig. 2 . In this case the finite-difference form of equation system (1.2) is

$$
\begin{aligned}
& \frac{\varphi_{i}^{n+1}-\varphi_{i}^{n}}{\Delta t}+\frac{1}{\rho_{1}} \frac{J_{i+1}^{n}-J_{i}^{n}}{\Delta z}=0 \\
& \frac{J_{i}^{n+1}-J_{i}^{n}}{\Delta t}+K_{1} \frac{\varphi_{t b}\left(1-\varphi_{t b}\right) J_{i}^{n}}{1+\varphi_{t b}\left(k_{\rho}-1\right)}+K_{2} \frac{\varphi_{t b}\left(1-\varphi_{t b}\right)}{1+\varphi_{t b}\left(k_{\rho}-1\right)} \\
& \quad+D \frac{\varphi_{t b}}{1+\varphi_{t b}\left(k_{\rho}-1\right)} \frac{\varphi_{i}^{n}-\varphi_{i-1}^{n}}{\Delta z}=0
\end{aligned}
$$

where $\varphi_{t b}=\frac{\varphi_{i}^{n}+\varphi_{i-1}^{n}}{2} ; i$ is the running index in the $z$ direction of space and $n$ is the running index in the $t$ time-direction.

From the (1.3) we note that the equation representing pressure distribution can be solved separately from (1.2). So, we will solve it on the same time level of function $\varphi, J$ after the two-lasts are determined. The finite-difference form for the pressure-equation is following 


$$
\frac{P_{i+1}^{n+1}-P_{i}^{n+1}}{\Delta z}+\rho_{1} g\left[k_{\rho}-\varphi_{i}^{n+1}\left(k_{\rho}-1\right)\right]-\left(k_{\rho}-1\right) \frac{J_{i}^{n+1}-J_{i}^{n}}{\Delta t}=0
$$

\section{b) The numerical solution}

The numerical solutions are obtained for the cases when the numerical values of parameters of equation system (1.2) in CGS units are:

$$
\begin{gathered}
L=50(\mathrm{~cm}) ; g=980\left(\mathrm{~cm} / \mathrm{s}^{2}\right) ; \rho_{2}=1.00\left(\mathrm{~g} / \mathrm{cm}^{3}\right) \\
K_{1}=1 \cdot 10^{4} ; D=1.47 \cdot 10^{4} ; \varphi_{0}=0.005 ; \Delta t=0.001(\mathrm{~s}) ; \Delta z=2.38(\mathrm{~cm}) \\
\text { 1. The particles are heavier than fluid phase } \\
k_{\rho}=0.997 ; \quad \text { (Fig. 3-4) }
\end{gathered}
$$

2. The particles are lighter than fluid phase

$$
k_{\rho}=1.003 \text {; (Fig. 5-6) }
$$

The results are showed in Fig. 3-6 for $\varphi=\varphi(z), J=J(z)$ at 3 different moments of time: $t=10,120,3600(\mathrm{~s})$.

The solution $\left.\varphi\right|_{t=\infty}=\varphi_{\text {inf }}(z)$ for stationary sedimentation and the numerical solution $\varphi=\varphi(z)$ at moment $t=3600$ (s) when the particles are heavier than fluid phase $\left(k_{\rho}=0.997\right)$ are showed in Fig. 8.

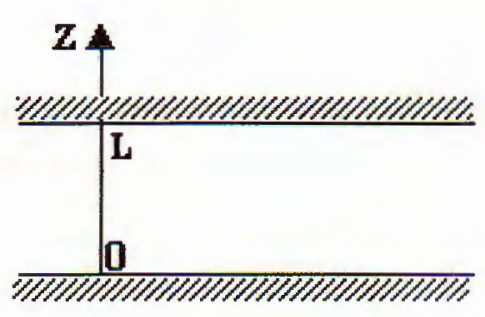

Fig. 1

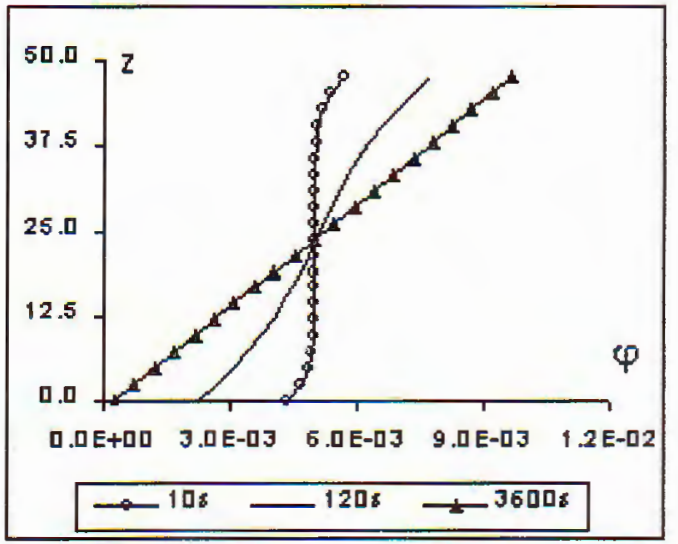

Fig. 3

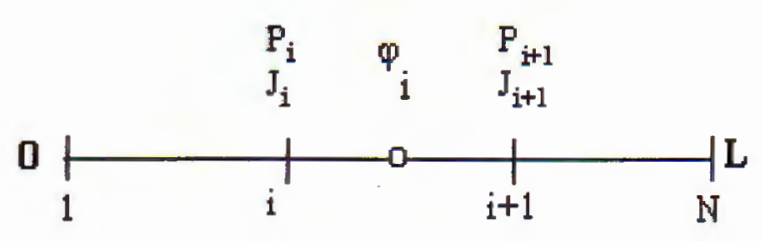

Fig. 2

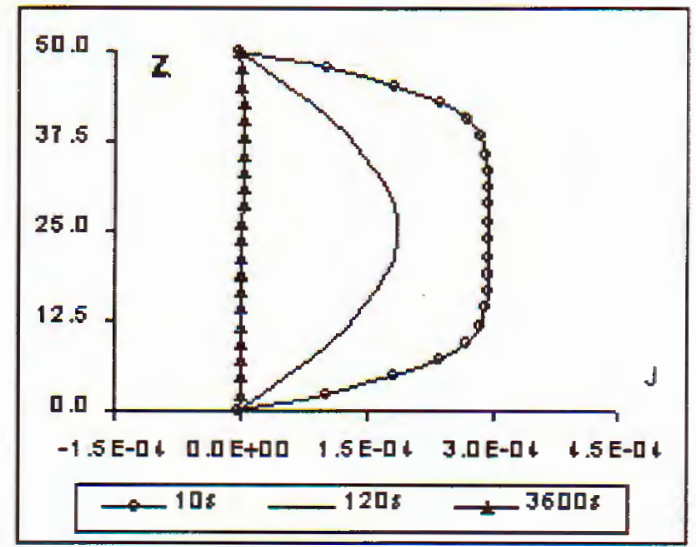

Fig. 4 


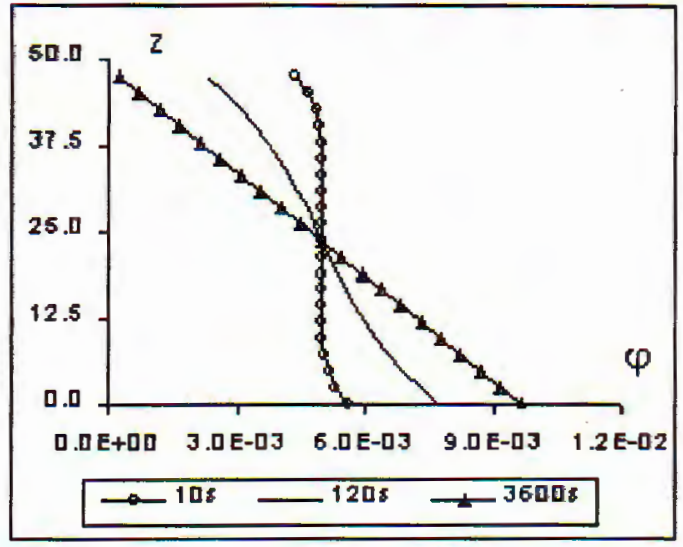

Fig. 5

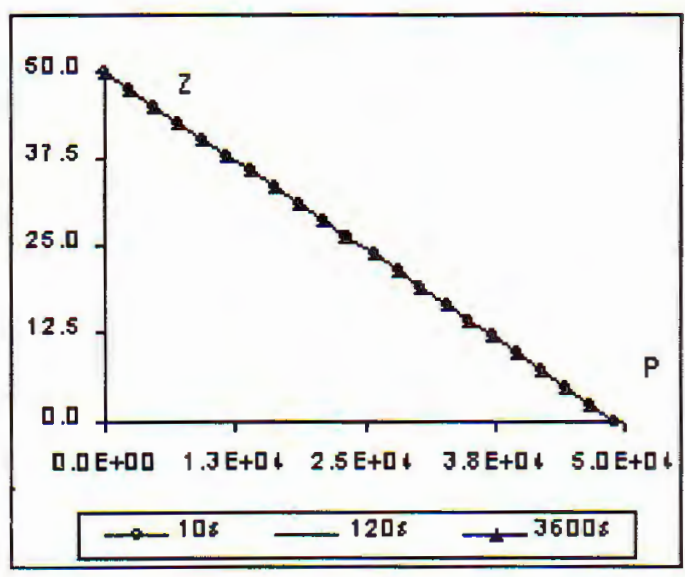

Fig. 7

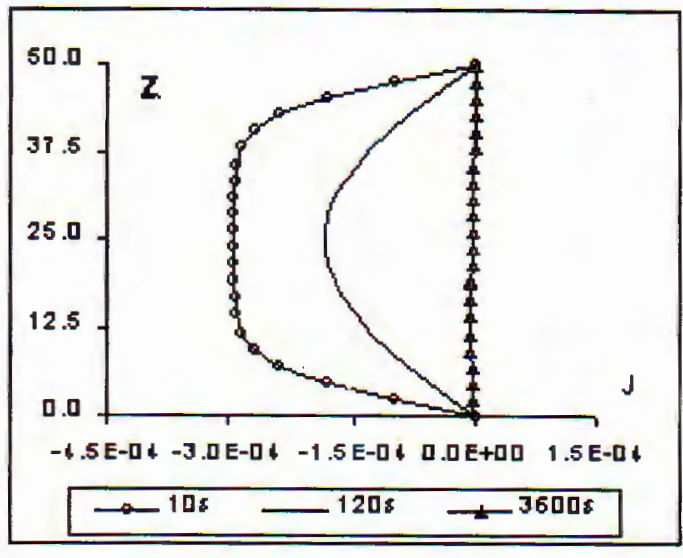

Fig. 6

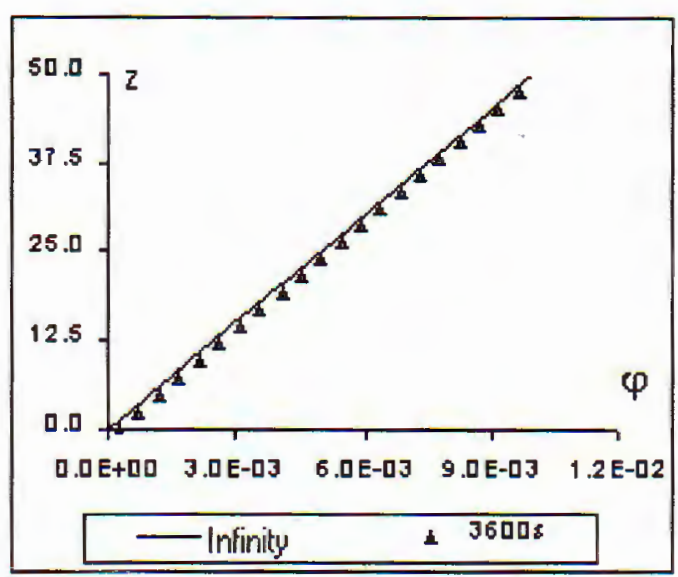

Fig. 8

\section{Conclusion}

From the results illustrated in Fig. 3-8 one can see that together with time growing, the particles will be concentrated more and more in the direction of upper plane if they are lighter than viscous fluid, and they will be concentrated in the direction to the bed in the opposite case.

Since average particle concentration in considered suspension is small and the difference between particle and fluid densities are not big, so hydrostatic pressure distribution is not influenced by particle distribution (Fig. 7).

The obtained results show that this model can be used for qualitative study of physical phenomenon of sedimentation problem. 
This work was financially supported by the Vietnamese Council of Natural Sciences.

\section{REFERENCES}

1. Nguyen Hong Phan, Nguyen Van Diep. Generalized diffusion theory of nonrotational, rigid spherical particle sedimentation in viscous fluid, Vietnam J. of Mechanics, 23 (2001), 159-166.

2. John H. Mathews. Numerical methods for Mathematics, Science, and Engineering, Prentice Hall, Inc. 1992.

3. C. A. J. Fletcher. Computational Techniques For Fluid Dynamics, SpringerVerlag, 1997.

Received November 10, 2001

\section{NGHIÊN CÚU SỐ BÀI TOÁN LẮNG ĐONG CỦA HẠT CÂUU RẮN KHÔNG QUAY TRONG CHẤT LỎNG NHỚT}

Bài báo này có thể coi như phần tiếp tục của bài báo [1], ở đó lý thuyết khuyếch tán suy rộng cho các hạt cầu cứng lắng đọng trong chất lơng nhớt dã được trình bày. Trong bài báo này, lời giải số cho bài toán lắng đọng không dừng đã được thu nhận. Phương pháp sai phân hiện đã được áp dụng để khắc phục tính phi tuyến của hệ phương trình cần giải. Các kết quả thu được cho thấy mô hình khuyếch tán suy rộng có thể sử dụng để nghiên cứu định tính các đặc trưng vật lý của quá trình lắng đọng. 